\title{
The effects of age and divided attention on spontaneous recognition
}

\author{
Benjamin A. Anderson • Larry L. Jacoby • \\ Ruthann C. Thomas • David A. Balota
}

Published online: 20 November 2010

(C) Psychonomic Society, Inc. 2010

\begin{abstract}
Studies of recognition typically involve tests in which the participant's memory for a stimulus is directly questioned. There are occasions however, in which memory occurs more spontaneously (e.g., an acquaintance seeming familiar out of context). Spontaneous recognition was investigated in a novel paradigm involving study of pictures and words followed by recognition judgments on stimuli with an old or new word superimposed over an old or new picture. Participants were instructed to make their recognition decision on either the picture or word and to ignore the distracting stimulus. Spontaneous recognition was measured as the influence of old vs. new distracters on target recognition. Across two experiments, older adults and younger adults placed under divided-attention showed a greater tendency to spontaneously recognize old distracters as compared to full-attention younger adults. The occurrence of spontaneous recognition is discussed in relation to ability to constrain retrieval to goal-relevant information.
\end{abstract}

Keywords Spontaneous recognition · Aging · Divided attention · Involuntary memory · Controlled processing . Retrieval constraint $\cdot$ Distraction control

\section{Introduction}

Although memory researchers have typically investigated voluntary memory by directly asking people to recall or

Portions of these findings were presented at the Cognitive Aging Conference, Atlanta, Georgia, April 2010.

B. A. Anderson $(\bowtie) \cdot$ L. L. Jacoby $\cdot$ R. C. Thomas $\cdot$ D. A. Balota Department of Psychology, Washington University,

St. Louis, MO 63130, USA

e-mail: banderson@wustl.edu recognize studied items, involuntary memory is common and at least as important as voluntary memory in daily life. As a commonplace example, one might encounter an acquaintance and spontaneously have a feeling of familiarity without memory for the acquaintance being directly questioned. There may be important differences between the memory processes underlying spontaneous recognition and recognition of the same acquaintance if memory had been directly questioned. The most obvious difference is that voluntary memory involves the attempt to remember whereas involuntary memory is more heavily driven by the stimulus.

Involuntary memory may be thought of as a more automatic as compared to a controlled memory process in that it occurs without intention. Mandler (1980) described encountering an acquaintance in a novel context (viz., his butcher on a bus) to illustrate the distinction between the experience of familiarity in "knowing" the acquaintance from somewhere and the retrieval attempt directed toward identifying the acquaintance. Although much research has explored how familiarity influences recognition memory performance when the participant has an explicit goal to remember (e.g., Jacoby, 1991; Jacoby, Woloshyn, \& Kelley, 1989), the "butcher on the bus" example demonstrates a type of spontaneous familiarity which appears to be involuntary. In that example, the spontaneous familiarity of the acquaintance captures attention (c.f., James, 1890; Johnston, Hawley, Plewe, Elliott, \& Dewitt, 1990), whereas familiarity in a recognition test occurs when attention is focused on the direct memory task. The two forms of familiarity might differ in that only spontaneous familiarity occurs without intention.

Measuring spontaneous recognition requires a means of assessing familiarity without directly asking participants to engage in a memory search. Previous research on implicit 
memory (for a review, see Roediger, 1990) employed "indirect" memory tests to reveal the influence of prior experience when a person has not been directed to engage in voluntary memory. For example, reading a word enhances later perceptual identification of the word when it is briefly flashed, even when the word is not recognized as having been earlier studied (Jacoby \& Dallas, 1981). These indirect tests reveal an unintentional use of memory, but such effects are often unaccompanied by any subjective experience of familiarity.

The dynamics of involuntary memory have primarily been investigated in the context of autobiographical recall. Based on research using self report and diary methods (e.g., Berntsen, 2007; Mace, 2006), involuntary autobiographical memories tend to be specific, externally driven by people, activities, objects, locations, topics, etc., and typically occur while in a non-focused state (e.g., Berntsen, 2007; Kvavilashvili \& Mandler, 2004). The involuntary memory examined in those studies is often more complete than the involuntary familiarity illustrated with the "butcher in the bus" example in that they involve rich details of the prior experience rather than being only a vague feeling of familiarity. To resolve the spontaneous familiarity in the "butcher-in-the-bus" example, consciously-controlled processing was necessary to identify the familiar person as being the butcher. In naturalistic settings, there are similar occasions wherein spontaneous familiarity is not resolved and one is left unable to identify why something seems familiar (Ball \& Little, 2006; Berntsen, 2010; Kvavilashvili, $\&$ Mandler, 2004). In this article, our focus is on involuntary familiarity of the butcher-in-the-bus variety although more complete forms of involuntary memory might also contribute to our results.

There is little work exploring the dynamics of spontaneous recognition memory in the laboratory. However, although not discussed as such, B. A. Eriksen, C. W. Eriksen, and Hoffman's (1986) use of a "flanker" procedure highlighted the distinction between spontaneous and directed recognition memory. In a procedure designed to investigate memory search processes, they presented sets of letters followed by a memory test that required participants to judge whether a probe letter was presented in the most recent set. The probe letter was flanked by either old letters from the memory set or new letters. Importantly, participants were instructed to ignore the flanking letters and base their judgment solely on the oldness of the probe letter. Consequently, any effect of the flanking letters can be considered involuntary and spontaneous. The oldness of the flanker influenced recognition of the probe. The memory judgment on the probe letter was slowed when it was surrounded by an incongruent flanker (e.g., an old probe letter flanked by new letters) compared to a congruent flanker (e.g., an old probe letter flanked by old letters). Further, there was a dissociation between directed and spontaneous recognition in the effect of memory set sizes on performance. Larger memory sets were associated with reduced recognition of the probe letter, but memory set size did not change the effect of flanker oldness on memory. The effect of flanking letters was said to be produced by their familiarity, which was independent of the memory search that was engaged to recognize probe letters.

In a study designed to investigate spontaneous recognition more directly, Ste-Marie and Jacoby (1993) used a similar flanker paradigm that involved words instead of letters. Spontaneous recognition was measured by comparing the influence of old compared to new flanker words on accuracy and response time of recognition judgments for the target word. If an old flanking word spontaneously gave rise to a feeling of familiarity, then it should influence the old/new decision made for the target word. The experiments included full and divided attention conditions during the recognition test to examine whether attention influenced the likelihood that spontaneous recognition would occur. Results showed that the oldness of the flankers had no influence on either response time or accuracy of performance when full attention was given to the recognition memory test. However, when attention was divided, response time was faster when the oldness of the target and flanker was congruent (e.g., old target paired with old compared to new distracter) and slowed when the oldness of the target was incongruent with the distracter (e.g., new target paired with old compared to new distracter).

The current studies further investigated spontaneous recognition by assessing whether the ability to constrain retrieval would influence the contribution of distracting stimuli to recognition memory decisions in a novel pictureword interference paradigm. Participants first studied a series of pictures and words followed by a memory test with each trial displaying an old or new word superimposed over an old or new picture. Participants were instructed to make their recognition decision on either the picture or word and to ignore the distracting stimulus (see Fig. 1). As in Ste-Marie and Jacoby (1993), the primary measure for spontaneous recognition was the influence of an old compared to a new distracter on old/new decisions for a target item. Familiarity of the distracter was expected to be spontaneous with its effect being automatic in the same way that word-reading influences color naming in the colorword Stroop (1935) task. Results from the Stroop task show that participants are slower and less accurate at naming the ink color when the color word is incongruent (e.g., the word "red" in green ink) as compared to congruent (e.g., the word "red" in red ink) (for a review, see MacLeod, 1991). As in the color-word Stroop task, spontaneous familiarity of the distracter was expected to influence 
Fig. 1 Schematic of the Memory Stroop task. Participants study a series of pictures and words and are then asked to make recognition decisions on the picture or word during separate test blocks. The example test stimuli represent the four item types that crossed old or new words with old or new pictures. The correct response to each of these items depended upon whether the recognition target was the picture or the word, as instructions indicated prior to each test block

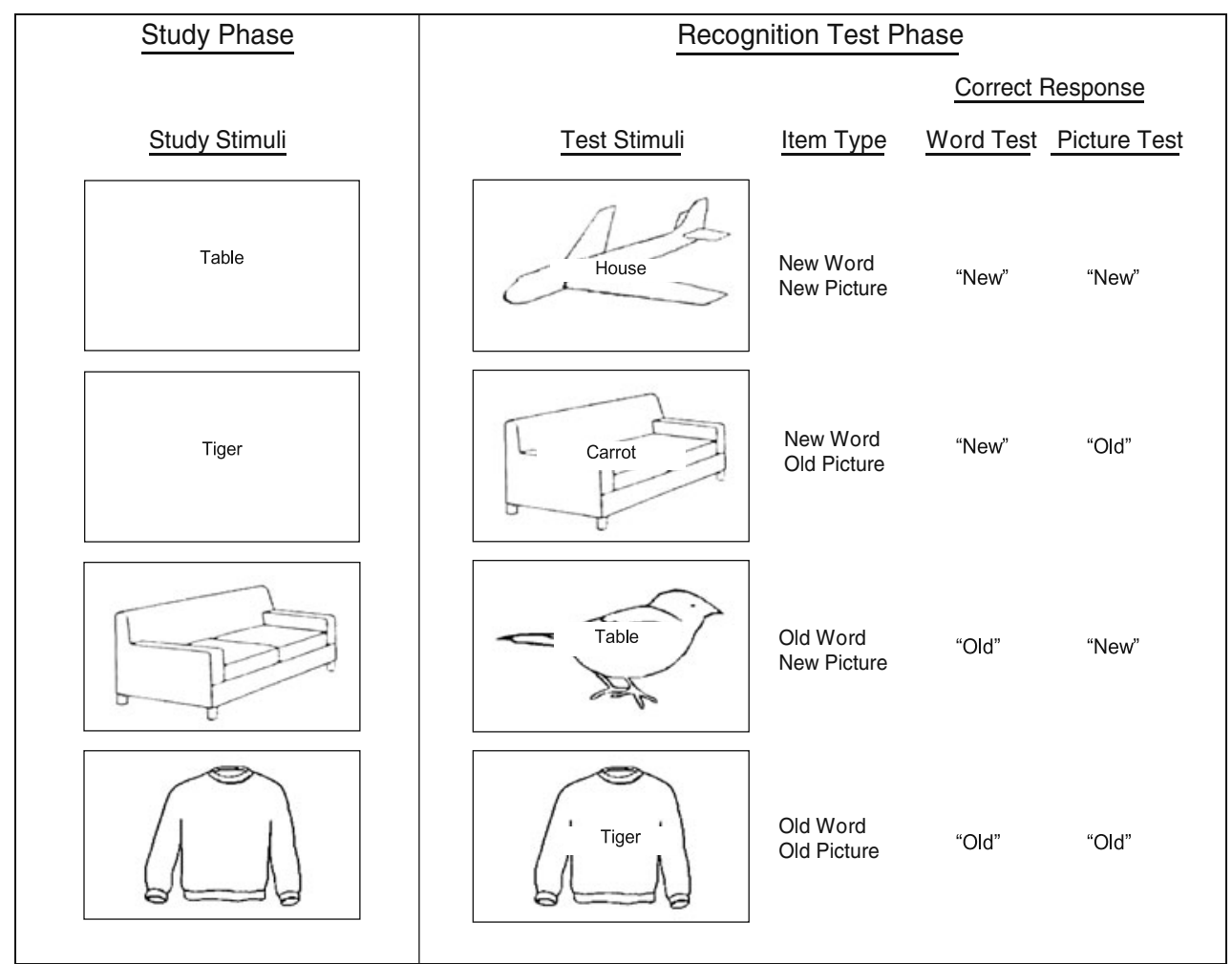

judgment of the target in the current paradigm. That is, spontaneous recognition of an old distracter was expected to lead to interference when paired with a new target (i.e., incongruent condition) and facilitation when paired with an old target (i.e., congruent condition). Despite the similarities, there are many differences between our procedure and those of color-word Stroop experiments. Among those, our "old" distracters were presented only once during study whereas participants in color-word Stroop experiments have had a long history of reading color words. Regardless, we will refer to our procedure as a "memory Stroop paradigm" as a short-hand device for reminding readers of the procedure and the underlying rationale.

The first experiment investigated age differences in spontaneous recognition during the Memory Stroop task. Older adults tend to show the greatest memory decrements in situations requiring deliberate, controlled processing (e.g., Craik \& Jennings, 1992), which is involved when directing memory toward source or contextual information as well as avoiding interference from distracting information (e.g., Balota, Cortese, Duchek, Adams, Roediger, McDermott, et al., 1999; Hasher \& Zacks, 1988; Jennings \& Jacoby, 1993, 1997; Mayr \& Kliegl, 2000; Yonelinas, 2002). Research investigating age differences in performance on color-word Stroop tasks suggests that older adults have difficulty engaging cognitive control to avoid automatically processing the more accessible word information (e.g., Mutter, Naylor, \& Patterson, 2005; Spieler, Balota, \& Faust,
1996). Likewise, older adults have difficulty controlling processing of irrelevant information when instructed to focus on a target task (Hasher, Lustig, \& Zacks, 2007). Rowe, Valderrama, Hasher, and Lenartowicz (2006) found that when target pictures were superimposed with distracting words in an initial task, aging was associated with greater subsequent implicit memory for the distracting words. These studies provide evidence of age differences in constraining attention to avoid interference from irrelevant information.

A deficit in controlled processing may result in a qualitatively different way of using memory during retrieval. The concept of source-constrained retrieval emphasizes the extent to which individuals rely on controlled (recollection) rather than automatic (familiarity) processes when performing on direct tests of memory. This work emphasizes how age differences in memory are potentially due to older adults' failure to utilize source information to direct retrieval, instead relying on less constrained fluency- or familiarity-based memory judgments (e.g., Jacoby, Shimizu, Daniels, \& Rhodes, 2005; Jacoby, Shimizu, Velanova, \& Rhodes, 2005; Marsh, Meeks, Cook, Clark-Foos, Hicks \& Brewer, 2009).

The second experiment aimed to replicate the observed spontaneous recognition in the Memory Stroop task, and extend the findings to another group of individuals with compromised use of controlled processes, namely, younger adults under divided attention during the memory test. Spontaneous recognition may be more likely to occur when an individual is less reliant upon controlled retrieval (Ste-Marie 
\& Jacoby, 1993), which aligns with evidence from autobiographical research showing that involuntary memory is likely to occur when in a non-focused state (e.g., Berntsen, 2007).

The aim of the current studies was to establish the relationship between retrieval constraint and spontaneous recognition of distracting information. If participants' processing were appropriately constrained to target information, then spontaneous recognition of the distracter would not arise and, so, not influence recognition memory. On the other hand, if participants' processing was not appropriately constrained, spontaneous recognition of tobe-ignored information (e.g., familiarity of a picture when the task is to judge oldness of a superimposed word) should influence recognition judgments, producing a Stroop-like effect. Given prior work on controlled retrieval, it was hypothesized that older adults and younger adults under divided attention would show greater spontaneous recognition of distracting information compared to young adults under full attention. Evidence for greater spontaneous recognition would be shown by a significant influence from old compared to new distracters on target recognition of pictures or words.

\section{Experiment 1}

\section{Methods}

\section{Participants}

Thirty-two healthy older adults $\left(M_{\text {age }}=76.6 ; M_{\text {vocabulary }}=\right.$ $35.9 ; M_{\text {education }}=15.1$ years) and 48 healthy younger adults $\left(M_{\text {age }}=19.6 ; M_{\text {vocabulary }}=33.7 ; M_{\text {education }}=13.6\right)$ participated in this study. Health and demographic information was collected prior to the experiment and vocabulary scores were collected after the experiment using the vocabulary subscale from the Shipley Institute of Living Scale (Shipley, 1986). The older adult participants were recruited from the community through the Washington University psychology department participant pool and the younger participants were recruited from the Washington University student participant pool. None of the older adults reported having previous stroke or head injury.

\section{Materials and design}

The overall design of this study was a 2 (target type: old, new) $\times 2$ (distracter type: old, new) $\times 2$ (test type: picture, word) $\times 2$ (age group: younger, older) mixed factorial, with target, distracter, and test type manipulated within subjects and age group as a between subjects factor. The influence of spontaneous recognition on memory performance was assessed by separate analyses on hits and false alarms. A schematic of the design and representative stimuli used in the experiment is shown in Fig. 1.

The experiment included 256 pictures and 256 words. Sixteen of these pictures and words were assigned to a practice round while the remaining 240 of each type were used in the experiment proper. The picture material set was courtesy of Michael J. Tarr, Brown University, http://www. tarrlab.org/ (see Rossion \& Pourtois, 2004). These pictures were all single line drawings of objects without background, shading, or color. The words were selected from the Elexicon database (Balota et al., 2007; http://elexicon. wustl.edu/). All words were nouns ranging from three to eight letters in length and presented in black 20 point Arial font.

Pictures and words were pseudo-randomly paired for the memory test with the only restriction being that the picture and word were not semantically related. The test lists were randomly ordered and identical across all participants. The test items were fully counterbalanced such that each item occurred equally often across participants in each condition (see Fig. 1).

The experiment consisted of ten runs, each of which included a study and test phase. Each study phase included a block of 12 randomly presented pictures and a block of 12 randomly presented words with the order of blocks varied across the experiment and counterbalanced across participants. Each test phase included two blocks of 12 items, with one block testing memory for pictures and the other testing memory for words. Each test block was made up of an equal number of the four item types with the condition that no more than two of the same item type occurred consecutively.

\section{Procedure}

The experiment began with task instructions followed by a brief practice round. Each of the ten study/test runs began with an instruction screen telling participants to study the following items (pictures or words). Study items were then presented one at a time on the center of the screen for 2.5 seconds with a $500 \mathrm{~ms}$ inter-stimulus interval (ISI). After the 12 items from the first stimulus type were shown, another instruction screen was presented with the other modality (i.e., picture or word).

Each recognition test phase included a separate block for memory judgments based on pictures or words. The instructions screen shown prior to each of these blocks instructed participants to only say "old" if the picture (or word) was previously studied and to ignore the other item. Instructions were shown in light green on a black background for the word instructions screen and shown in red on black background for the picture instructions screen. Participants then pressed a button on the keyboard to 
indicate "old" or "new" to each of the 24 test items. The test display consisted of an old or new picture with an old or new word superimposed in its center. The test stimulus appeared within a white box that was randomly presented in one of four slightly off center quadrants on a screen with a blue background. Participants were given up to six seconds to make their response. After the participant's response or the exhaustion of the six seconds, the screen cleared for an ISI of $500 \mathrm{~ms}$ and the next trial began. This same procedure consisting of instructions, study blocks, and test blocks was repeated ten times across the experiment with a break occurring half way through.

Results and discussion

The influence of spontaneous recognition was assessed with accuracy of memory judgments. Although response times for memory judgments were also recorded, there was high variability due to limited number of observations. The pattern of those results did not contradict or extend the conclusions based on analyses of hits and false alarms. Thus, response time data are not reported. Unless otherwise noted, significance for all reported statistics was $p<0.05$.

As described above, spontaneous recognition is evidenced by a significant influence of old compared to new distracters on memory judgments of the target picture or word. Spontaneous recognition of old distracters can be seen by either an increase in hits when responding to old targets or an increase in false alarms when responding to new targets. Table 1 shows recognition accuracy in the probability of responding "old" to items as a function of group (younger adults vs. older adults), test type (picture vs. word), target status (old vs. new), and distracter status (old vs. new) with hits on the left and false alarms on the right side of the table. Separate mixed factorial ANOVAs were conducted on hits and false alarms to assess spontaneous recognition with test type and distracter type as a repeated measures variable and group as a between subjects variable.

The analysis of hits (left side of Table 1) revealed a significant interaction between test type (picture or word), distracter (old/new), and group (older vs. young), $F(1,78)=$ $6.73, p=0.011, \eta_{p}{ }^{2}=0.079$. To examine this interaction, separate $2 \times 2$ ANOVAs on distracter and group were conducted for the picture and word tests. For the picture test, no significant main effect or interaction was found. In contrast, the analysis of performance on the word test revealed a main effect of group, with fewer hits for older as compared to younger adults, $F(1,78)=11.66, p=0.001$, $\eta_{p}{ }^{2}=0.130$. The main effect of distracter was significant, with fewer hits for old targets paired with new compared to old distracters, $F(1,78)=7.99, p=0.006, \eta_{p}{ }^{2}=0.093$. Most important, the Distracter $\mathrm{x}$ Group interaction was also significant, $F(1,78)=4.22, p=0.043, \eta_{p}{ }^{2}=0.051$. Paired sample one-tailed $t$-tests demonstrated that for older adults, hit rate increased for targets paired with old rather than new distracters $(0.72$ vs. 0.64$), t(31)=2.57, p=0.008$, but remained stable for younger adults $(0.80$ vs. 0.79$), t(47)<1$. In sum, analyses of hits revealed evidence of spontaneous recognition only for older adults in the condition in which words were targets.

The analysis of false alarms (right side of Table 1) revealed a non-significant overall difference between older $(0.13)$ and younger $(0.10)$ adults, $F(1,78)=2.58, p=0.11$. False alarms were higher in the word than the picture test, $F(1,78)=51.33, p<0.001, \eta_{p}{ }^{2}=0.397$, and higher for new targets paired with old rather than new distracters, $F(1,78)=7.99, p<0.001, \eta_{p}{ }^{2}=0.290$. Further, the effect of the oldness of distracters on false alarms was larger in the word test than in the picture test, $F(1,78)=4.24, p=0.043$, $\eta_{p}{ }^{2}=0.052$, for the Distracter $\mathrm{x}$ Test Type interaction. Most important, there was a marginally significant Distracter $\mathrm{x}$ Group interaction, $F(1,78)=3.48, p=0.066, \eta_{p}{ }^{2}=0.043$. Paired sample one-tailed $t$-tests were conducted in order to explore the nature of this interaction. The increase in false alarms to targets paired with old rather than new distracters was somewhat larger for older adults $(0.16$ vs. 0.10$)$, than for younger adults ( 0.12 vs. 0.09$)$, but the difference was significant for both older and younger adults, $p<0.001$. In sum, analyses of false alarms revealed interference effects for both older and younger adults, providing evidence of spontaneous recognition when new targets were paired with
Table 1 Probability of judging an item as "old" as a function of target, distracter, test type, and group in Experiment 1

in parentheses

\begin{tabular}{llllll}
\hline Group & \multicolumn{2}{l}{ Old target } & & \multicolumn{2}{l}{ New target } \\
\cline { 2 - 3 } \cline { 5 - 6 } & New distracter & Old distracter & & New distracter & Old distracter \\
\cline { 5 - 6 } & & Picture trials & & \\
Young & $0.90(0.08)$ & $0.92(0.08)$ & & $0.04(0.05)$ & $0.06(0.06)$ \\
Older & $0.93(0.06)$ & $0.92(0.09)$ & & $0.06(0.08)$ & $0.11(0.10)$ \\
Young & $0.79(0.13)$ & Word trials & & & \\
Older & $0.64(0.22)$ & $0.80(0.13)$ & & $0.13(0.12)$ & $0.17(0.15)$ \\
\hline
\end{tabular}


old rather than new distracters. This effect of old distracters showed a trend toward interacting with age, such that older adults were more prone to spontaneously recognizing distracting information.

Results from Experiment 1 showed age differences in spontaneous recognition of old distracters. Older adults' recognition of old target words was facilitated when targets were paired with old rather than new distracter pictures. However, spontaneous recognition was not observed for older adults when judging old pictures. Older adults' false alarms revealed spontaneous recognition of distracters when both pictures and words served as targets. In contrast, younger adults were generally less likely to spontaneously recognize old distracters but showed evidence for spontaneous recognition when judging new targets.

Spontaneous recognition was more likely to occur for older adults when words were the target for the recognition-memory test. It is potentially important that the probability of a hit was lower for older than for young adults only when the recognition memory of words was judged. This correspondence between reduced recognition and increased spontaneous recognition might be taken to suggest that age differences in encoding of items that subsequently served as targets was responsible for differences in spontaneous recognition. However, we consider the possibility that differences in spontaneous recognition are, at least partially, reliant on age differences in retrieval processes. That is, we hold that older adults are less able to constrain retrieval processes than are young adults and, so, are more vulnerable to spontaneous recognition of to-beignored information.

To gain support for the importance of constraining retrieval, we examined the effects of dividing attention of young adults at the time of test in Experiment 2. We expected dividing attention at test to produce results for young adults that are similar to those found for older adults under conditions of full attention. A finding of this sort would provide evidence that attention is required to constrain retrieval processes, and suggest that the greater spontaneous recognition of older adults as compared to young adults tested under conditions of full attention is owed in part to a lessened ability to constrain retrieval processes.

\section{Experiment 2}

The second experiment was designed to replicate the age differences in spontaneous recognition observed in the first experiment. Also, it included a group of younger adults placed under divided attention conditions during test. Prior work has shown that younger adults under divided attention show similar memory performance to older adults tested with full attention (Anderson, Craik, \& Naveh-Benjamin, 1998; Craik, 1982, 1983). The influence of divided attention on task performance is especially pronounced when tasks require controlled processing (Hicks \& Marsh, 2000; Jacoby, 1991; Moscovitch, 1994). Dividing attention during test has been found to influence the ability to use recollection, while leaving familiarity unaltered (e.g., Jacoby, 1991; Skinner \& Fernandes, 2008; Ste-Marie \& Jacoby, 1993). Along these lines, Ste-Marie and Jacoby (1993) showed that spontaneous recognition of distracting words in a flanker task was only observed when dividing young adults' attention. Thus, we expected that dividing attention at test would increase spontaneous recognition of distracting information in young adults.

Methods

\section{Participants}

Participants were 24 older adults $\left(M_{\text {age }}=74.8 ; M_{\text {vocabulary }}=\right.$ $34.5 ; M_{\text {education }}=14.7$ years) and 48 younger adults. The younger adults were randomly assigned to the full-attention or divided-attention condition $\left(M_{\text {age }}=20\right.$ and $19.8 ; M_{\text {vocabulary }}=$ 33.4 and $32.0 ; M_{\text {education }}=13.9$ and 13.6; respectively). The older adult participants were recruited from the community and the younger participants were recruited from the Washington University student participant pool. None of the older adults reported having previous stroke or head injury.

\section{Materials and design}

The materials and design were the same as in Experiment 1 with two exceptions. First, pictures and words were intermixed (rather than blocked) during study with no more than three presentations of the same stimulus type in sequence. Second, Experiment 2 included a group of younger adults placed under divided attention during test. In the divided attention task (see Craik, 1982; Ste-Marie \& Jacoby, 1993), participants monitored a recorded list of digits to detect sequences of three consecutive odd digits (e.g., 5, 7, 9). The digits were random with the constraint that at least one but no more than five digits occurred between target sequences. The presentation rate ( 1 per second) of each digit and the randomization of digit sequences was controlled via Adobe Audition 1.5. Participants were instructed to say "now" each time a sequence occurred and the experimenter monitored the participant's accuracy. If a sequence was missed, the experimenter said "missed" to remind the participant to maintain accuracy on the task.

\section{Results and discussion}

As in Experiment 1, response times for memory judgments are not reported as the pattern of findings neither contradicted nor extended the findings based on hits and false 
alarms. Participants generally performed well on the digitmonitoring task in the divided attention condition, with monitoring accuracy being at least $0.60(M=0.75, S D=$ 0.09). Unless otherwise noted, significance for all reported statistics indicates $p<0.05$.

Table 2 displays the probability of responding "old" to items as a function of group (full-attention young, dividedattention young, older adults), test type (picture vs. word recognition), target status (old vs. new), and distracter status (old vs. new). Analyses were conducted in a similar fashion to those described for Experiment 1, with separate ANOVAs for hits and false alarms to examine spontaneous recognition.

Hit rates for old targets paired with old vs. new distracters are displayed on the left side of Table 2. The interaction between test type, distracter, and group $F(2,69)=5.66, p=$ $0.005, \eta_{p}^{2}=0.141$, was significant. To examine this interaction, separate $2 \times 3$ ANOVAs that included distracter and group as factors were conducted for the picture and word tests. For the picture test, only the main effect of group was significant, $F(2,69)=5.89, p=0.004, \eta_{p}{ }^{2}=0.146$, with greater hits for older adults and younger adults tested under full attention compared to younger adults tested under divided attention (all other $F_{S}<1$ ). Analyses of hits for the word test yielded a main effect of group, $F(2,69)=6.39$, $p=0.003, \eta_{p}{ }^{2}=0.156$, and distracter, $F(1,69)=14.69, p<$ $0.001, \eta_{p}{ }^{2}=0.176$ as well as a significant interaction between distracter type and group, $F(2,69)=5.92, p=0.004$, $\eta_{p}{ }^{2}=0.146$. Paired sample one-tailed $t$-tests indicated that there was a significant increase in hit rate to old words paired with old vs. new pictures for older adults (0.71 vs. 0.65), $t(23)=1.99, p=0.029$, and divided attention young adults (0.64 vs. 0.52$), t(23)=4.33, p<0.001$, but not for full attention young adults $(0.75$ vs. 0.76$), t(23)=0.312, p=$ 0.379 . In sum, analyses of hits revealed evidence of spontaneous recognition only for older adults and divided attention young in the condition in which words were targets.

False alarm rates for new targets paired with old vs. new distracters are displayed on the right side of Table 2. The analysis on false alarms yielded main effects test type, $F(1,69)=24.07, p<0.001, \eta_{p}{ }^{2}=0.259$, distracter, $F(1,69)=$ $18.58, p<0.001, \eta_{p}{ }^{2}=0.212$, and group, $F(2,69)=5.66, p=$ $0.005, \eta_{p}{ }^{2}=0.141$. Also, a significant interaction between test type and distracter shows that old distracters had a larger influence on false alarms in the word compared to the picture test, $F(1,69)=6.89, p=0.011, \eta_{p}^{2}=0.091$.

Most important, there was a significant interaction between distracter type and group, $F(2,69)=6.91, p=$ $0.002, \eta_{p}{ }^{2}=0.167$. Paired sample one-tailed $t$-tests revealed a significant increase in false alarms produced by old as compared to new distracters for older adults (0.13 vs. 0.07$)$, $t(23)=3.93, p<0.001$, and for divided attention young adults $(0.19$ vs. 0.13$), t(23)=3.59, p<0.001$. In contrast, full attention young adults' false alarm rate was not influenced by the oldness of the distracter $(0.07$ vs. 0.08$)$, $t(23)=0.637, p=0.265$.

In sum, spontaneous recognition was reflected by a significant increase in hit rates for words paired with old rather than new distracter pictures for older adults and younger adults tested under divided attention. Further, when judging new targets, spontaneous recognition of old distracters significantly increased the tendency to false alarm for older adults and younger adults tested under divided attention. Younger adults tested under full attention were not significantly influenced by the oldness of the distracting information, in line with results from Experiment 1.

These results suggest that spontaneous recognition cannot be wholly attributed to a difference in encoding. Importantly, younger adults assigned to the full- vs. divided-attention conditions did not likely differ at encoding since divided attention was manipulated during the memory test phase. Further, full-attention older and younger adults did not differ in their recognition of old pictures, but only older adults showed greater false alarms to new pictures paired with old as compared to new distracter words. As will be discussed, both age and divided attention are associated with decreases in controlled
Table 2 Probability of judging an item as "old" as a function of target, distracter, test type, and group in Experiment 2

Standard deviations are shown in parentheses

\begin{tabular}{llllll}
\hline Group & \multicolumn{3}{l}{ Old target } & & \multicolumn{2}{l}{ New target } & \\
\cline { 2 - 3 } \cline { 5 - 6 } & New distracter & Old distracter & & New distracter & Old distracter \\
\hline & & Picture trials & & \\
Full attention young & $0.85(0.13)$ & $0.87(0.14)$ & & $0.07(0.13)$ & $0.05(0.08)$ \\
Divided attention young & $0.80(0.14)$ & $0.79(0.16)$ & & $0.10(0.06)$ & $0.14(0.10)$ \\
Older adults & $0.91(0.12)$ & $0.93(0.08)$ & & $0.06(0.07)$ & $0.10(0.11)$ \\
& & Word trials & & \\
Full attention young & $0.76(0.17)$ & $0.75(0.17)$ & & $0.09(0.10)$ & $0.09(0.09)$ \\
Divided attention young & $0.52(0.18)$ & $0.64(0.14)$ & & $0.16(0.13)$ & $0.23(0.15)$ \\
Older adults & $0.65(0.19)$ & $0.71(0.21)$ & & $0.08(0.08)$ & $0.16(0.15)$ \\
\hline
\end{tabular}


processing. We argue that reduced ability to constrain retrieval is critical for the occurrence of spontaneous recognition.

\section{General discussion}

The current studies investigated spontaneous recognition using a novel Memory Stroop paradigm to determine how the oldness of to-be-ignored items influenced recognition of target items. As hypothesized, we found that older adults and younger adults tested under divided attention showed spontaneous recognition. When the distracting item was old, there was an increase in false alarms to new targets as well as an increase in hits to old targets. Thus, spontaneous recognition of distracters both interfered with and facilitated memory for the target. In contrast, young adults showed little evidence of spontaneous recognition of distracters. Results across both experiments suggest that spontaneous recognition is more likely to occur when the ability to engage in controlled retrieval processes is compromised, as in older adults and younger adults tested under divided attention. This research corresponds with previous work (Eriksen et al., 1986; Ste-Marie \& Jacoby, 1993) to demonstrate how the influence of old vs. new distracters on target recognition can be used as an index of spontaneous recognition.

Evidence of spontaneous recognition was most likely to be observed when memory performance was poor, with largest effects being observed when words were targets for older adults and young adults tested under conditions of divided attention. The superior recognition of pictures over words is in line with the picture superiority effect (Ally et al., 2008; Madigan, 1983; Paivio, 1969). Further, older adults and younger adults tested under divided attention generally showed less spontaneous recognition of distracting words compared to pictures, especially when making judgments on old pictures. These results may have been due to pictures being more memorable or distinctive than words (e.g., Dodson \& Schacter, 2002; Gallo, Cotel, Moore, \& Schacter, 2007; Schacter, Israel, \& Racine, 1999). It should be noted that the lack of facilitation effects found when judging old pictures makes it difficult to determine whether participants were more effectively constraining to the source when judging pictures, or alternatively, were responding on the basis of familiarity. However, the greater spontaneous recognition found for older adults and divided attention younger adults when responding to new picture targets paired with old word distracters suggests that those groups were less effective in constraining retrieval to the relevant information.

While the overall pattern of results suggests that encoding of information required for the target task serves a role in spontaneous recognition, our results also provide evidence of the importance of retrieval processes. In Experiment 2, young and older adults did not differ in either hits or false alarms to pictures when the distracting word was new. However, older adults showed an increased tendency to false alarm to pictures when the distracting word was old. The effect of dividing attention at test on false alarms for young adults also implicates the importance of retrieval processes. The full- and divided-attention younger adults would not be expected to differ in their encoding of items that later served as targets, but dividing attention at test resulted in participants being less able to retrieve the relevant encoded information. It is likely that either poor encoding of target information or poor ability to retrieve relevant information at the time of test is conducive to spontaneous recognition produced by distracting events. In this vein, naturalistic investigations of involuntary memory suggest that spontaneous retrieval often occurs when a person is in an unfocused state of mind (e.g., Berntsen, 2007), a condition similar to that produced by our manipulation of divided attention at test.

Our results suggest that controlled processing is required to avoid Stroop-like effects at the time of test and also that older adults are less able to engage such processing. The notion of source-constrained retrieval provides a way of understanding the ability to avoid unwanted influences of memory. When retrieval is constrained by source information, the resultant early selection of relevant information prevents the influence of irrelevant information on memory judgments (e.g., Jacoby et al., 2005b; Jacoby, Kelley, \& McElree, 1999; Marsh et al., 2009). Jacoby et al. (2005b) provided evidence that older adults are less able to engage in source-constrained retrieval than are young adults. Results from neuroimaging studies corroborate this conclusion. For example, a recent ERP study by Duverne, Motamedinia, and Rugg (2009) investigated age related differences when orientating retrieval toward items that were previously studied as either pictures or words. Results indicated that younger adults were more likely than older adults to orient retrieval toward the cued source of information (picture or word), as evidenced by age differences in activation of brain regions selectively involved in processing such source information (also see Morcom \& Rugg, 2004).

In a similar vein, Braver and colleagues (e.g., Braver, Rush, Satpute, \& Barch, 2005; Paxton, Barch, Racine, \& Braver, 2008) highlight a distinction between "proactive" (i.e., pre-retrieval) and "reactive" (i.e., post-retrieval) processes in studies of aging and cognitive control. Results from their research suggest that proactive control is more effective than is reactive control as a means of avoiding interference from distracting information (also see Burgess \& Shallice, 1996; Milham et al., 2002; Moscovitch \& Melo, 
1997; Norman \& Bobrow, 1979). Retrieval constraint is a proactive control process in that it allows memory search to be restricted to relevant information-in the present case, either the word or the picture. Results from other prior studies also suggest that older adults and divided attention younger adults are less able to constrain retrieval to relevant information, and, so, are more reliant on familiarity as a basis for responding (e.g., Jacoby, 1991; Jacoby et al., 2005b; Jacoby et al., 1989).

The observed age differences in spontaneous recognition converge with results demonstrating an age-related deficit in distraction control (Hasher et al., 2007). Prior studies have shown that older adults' performance on a target task is more disrupted by the presence of distracting information (Connelly, Hasher, \& Zacks, 1991; Duchek, Balota, \& Thessing, 1998; Dywan \& Murphy, 1996; Lustig, Hasher, \& Tonev, 2006). Likewise, older adults are more likely to encode and continue to access irrelevant information in subsequent tasks. Campbell, Hasher, and Thomas (2010) found that prior exposure to target pictures paired with distracting words improved older adults' later encoding and cued-recall of the same picture-word pairs, even though participants showed no explicit memory for the previous pairings. Thus, the results from the current studies align well with research on distraction control to suggest that distracting information is more likely to influence older adults' than younger adults' performance on a target task.

To what extent was spontaneous recognition accompanied by awareness of the source of the involuntary feeling of familiarity? In more naturalistic cases (e.g., Berntsen, 2007, 2010), involuntary memory often involves recollection of episodic details. However, such awareness of the source may not be required for effects of spontaneous familiarity. For example, Jacoby and Whitehouse (1989) found that participants were more likely to falsely recognize words when the same word (i.e., a context word) had been flashed immediately before the target of the recognition judgment. The preceding context word created a false sense of familiarity for the new target word, yet participants were unaware that the context word had been flashed. These results suggest that spontaneous familiarity may influence recognition memory even when participants are not aware of its source. In the current experiments, familiarity from the distracting information may have been misattributed to the target without participants' awareness of the distracting stimulus or its effects on judgment of the target. Alternatively, older adults and younger adults tested under divided attention may have been aware of the oldness of the distraction but unable to avoid the unwanted influence of this familiarity on target judgments. Further research is needed to address the issue of awareness in spontaneous recognition.

In sum, results from the current studies suggest that spontaneous recognition is more likely to occur when retrieval is not appropriately constrained to target information in a memory task. In particular, spontaneous recognition of distracters had greater influence on memory judgments of target stimuli for older adults and young adults tested under divided attention than for younger adults tested under full attention. However, there may be contexts that encourage spontaneous recognition even when young adults are fully attending to the memory task. For example, younger adults may spontaneously recognize distracting information when the target of the memory task frequently switches to the previously distracting stimulus type during test, making it more difficult to constrain retrieval processes. Further, involuntary memory in daily life has been reported to occur across a variety of contexts that vary in the extent to which memory is actively engaged in the ongoing task (e.g., Ball \& Little, 2006). Another important question is whether spontaneous familiarity operates in a similar way when it occurs outside of a memory task.

In conclusion, involuntary (spontaneous) memory is ubiquitous in daily life, but rarely studied in the laboratory (e.g., Berntsen, 2007; Kvavilashvili \& Mandler, 2004; Mace, 2006; Ste-Marie \& Jacoby, 1993). With the introduction of the Memory Stroop paradigm, the current studies provide a means of addressing unanswered questions about spontaneous recognition in an experimental setting. Our results suggest that spontaneous recognition is more likely to occur when retrieval is not appropriately constrained to relevant information in the environment. More generally, we might gain further insight into the elusive phenomenon of spontaneous recognition by considering how cognitive control sets the stage for its occurrence.

Acknowledgments This research was supported by National Institute on Aging Grant RO1AG13845. We would like to thank Carlee Beth Hawkins, Danielle Hirschfeld, Carole Jacoby, and Shari Steinman, for their assistance with data collection, and Andrea Hughes for helpful comments while developing this project.

\section{References}

Ally, B. A., Waring, J. D., Beth, E. H., McKeever, J. D., Millberg, W. P., \& Budson, A. E. (2008). Aging memory for pictures: Using high-density event-related potentials to understand the effect of aging on the picture superiority effect and the dynamics of recognition memory. Neuropsychologia, 46, 679-689.

Anderson, N. D., Craik, F. I. M., \& Naveh-Benjamin, M. (1998). The attentional demands of encoding and retrieval in younger and older adults: 1. Evidence from divided attention costs. Psychology and Aging, 13, 405-423.

Ball, C. T., \& Little, J. R. (2006). A comparison of involuntary memory retrievals. Applied Cognitive Psychology, 20, 11671179.

Balota, D. A., Cortese, M. J., Duchek, J. M., Adams, D., Roediger, H. L., III, McDermott, K. B., et al. (1999). Veridical and false memories in healthy older adults and in dementia of the Alzheimer's type. Cognitive Neuropsychology, 16, 361-384. 
Balota, D. A., Yap, M. J., Cortese, M. J., Hutchison, K. I., Kessler, B., Loftis, B., et al. (2007). The English lexicon project. Behavior Research Methods, 39, 445-459.

Berntsen, D. (2007). Involuntary autobiographical memories: Speculations, findings, and an attempt to integrate them. In J. H. Mace (Ed.), Involuntary memory (pp. 20-49). Malden, MA: Blackwell.

Berntsen, D. (2010). The unbidden past: Involuntary autobiographical memories as a basic mode of remembering. Current Directions in Psychological Science, 19(3), 138-142.

Braver, T. S., Rush, B. K., Satpute, A. B., \& Barch, D. M. (2005). Context processing and context maintenance in healthy aging and early stage dementia of the Alzheimer's type. Psychology and Aging, 20, 33-46.

Burgess, P. W., \& Shallice, T. (1996). Confabulation and the control of recollection. Memory, 4(4), 359-411.

Campbell, K. L., Hasher, L., \& Thomas, R. C. (2010). Hyper-binding: A unique age effect. Psychological Science, 21, 399-405.

Connelly, S. L., Hasher, L., \& Zacks, R. T. (1991). Age and reading: The impact of distraction. Psychology and Aging, 6, 533-541.

Craik, F. I. M. (1982). Selective changes in encoding as a function of reduced processing capacity. In F. Klix, J. Hoffman, \& E. van der Meer (Eds.), Cognitive research in psychology (pp. 152-161). Berlin: Deutscher Verlag der Wissenschaffen.

Craik, F. I. M. (1983). Age differences in remembering. In N. Butters \& L. R. Squire (Eds.), The neuropsychology of memory (pp. 3-12). New York: Guildford Press.

Craik, F. I. M., \& Jennings, J. M. (1992). Human memory. In F. I. M. Craik \& T. A. Salthouse (Eds.), The handbook of aging and cognition (pp. 51-110). Hillsdale, NJ: Lawrence Erlbaum Associates, Inc.

Dodson, C. S., \& Schacter, D. L. (2002). When false recognition meets metacognition: The distinctiveness heuristic. Journal of Memory and Language, 46, 782-803.

Duchek, J. M., Balota, D. A., \& Thessing, V. C. (1998). Inhibition of visual and conceptual information during reading in healthy aging and Alzheimer's disease. Aging, Neuropsychology, and Cognition, 5, 169-181.

Duverne, S., Motamedinia, S., \& Rugg, M. D. (2009). Effects of age on the neural correlates of retrieval cue processing are modulated by task demands. Journal of Cognitive Neuroscience, 21, 1-17.

Dywan, J., \& Murphy, W. E. (1996). Aging and inhibitory control in text comprehension. Psychology and Aging, 11, 199-206.

Eriksen, B. A., Eriksen, C. W., \& Hoffman, J. E. (1986). Recognition memory and attentional selection: Serial scanning is not enough. Journal of Experimental Psychology: Human Perception and Performance, 12, 476-483.

Gallo, D. A., Cotel, S. C., Moore, C. D., \& Schacter, D. L. (2007). Aging can spare recollection-based retrieval monitoring: The importance of event distinctiveness. Psychology and Aging, 22, 209-213.

Hasher, L., Lustig, C., \& Zacks, R. T. (2007). Inhibitory mechanisms and the control of attention. In A. Conway, C. Jarrold, M. Kane, A. Miyake, \& J. Towse (Eds.), Variation in working memory (pp. 227-249). New York: Oxford University Press.

Hasher, L., \& Zacks, R. T. (1988). Working memory, comprehension, and aging: A review and a new view. In G. G. Bower (Ed.), The psychology of learning and motivation (Vol. 22) (pp. 193-225). San Diego, CA: Academic Press

Hicks, J. L., \& Marsh, R. L. (2000). Toward specifying the attentional demands of recognition memory. Journal of Experimental Psychology. Learning, Memory, and Cognition, 26, 1483-1498.

Jacoby, L. L. (1991). A process dissociation framework: Separating automatic from intentional uses of memory. Journal of Memory and Language, 30, 513-541.

Jacoby, L. L., \& Dallas, M. (1981). On the relationship between autobiographical memory and perceptual learning. Journal of Experimental Psychology: General, 3, 306-340.
Jacoby, L. L., Kelley, C. M., \& McElree, B. D. (1999). The role of cognitive control: Early selection versus late correction. In S. Chaiken \& Y. Trope (Eds.), Dual-process theories in social psychology (pp. 383-400). New York: The Guilford Press.

Jacoby, L. L., Shimizu, Y., Daniels, K. A., \& Rhodes, M. G. (2005). Modes of cognitive control in recognition and source memory: Depth of retrieval. Psychonomic Bulletin \& Review, 12, 852-857.

Jacoby, L. L., Shimizu, Y., Velanova, K., \& Rhodes, M. G. (2005). Age differences in depth of retrieval: Memory for foils. Journal of Memory and Language, 52, 493-504.

Jacoby, L. L., \& Whitehouse, K. (1989). An illusion of memory: False recognition influenced by unconscious perception. Journal of Experimental Psychology: General, 118, 126-135.

Jacoby, L. L., Woloshyn, V., \& Kelley, C. (1989). Becoming famous without being recognized: Unconscious influences of memory produced by dividing attention. Journal of Experimental Psychology: General, 118, 115-125.

James, W. (1890). The principles of psychology (vol. 1). New York: Henry Holt \& Co.

Jennings, J. M., \& Jacoby, L. L. (1993). Automatic versus intentional uses of memory: Aging, attention, and control. Psychology and Aging, 8, 283-293.

Jennings, J. M., \& Jacoby, L. L. (1997). An opposition procedure for detecting age-related deficits in recollection: Telling effects of repetition. Psychology and Aging, 12, 352-361.

Johnston, W. A., Hawley, K. J., Plewe, S. H., Elliott, J. M. G., \& Dewitt, M. J. (1990). Attention capture by novel stimuli. Journal of Experimental Psychology: General, 119, 397-411.

Kvavilashvili, L., \& Mandler, G. (2004). Out of one's mind: A study of involuntary semantic memories. Cognitive Psychology, 48, 47-94.

Lustig, C., Hasher, L., \& Tonev, S. T. (2006). Distraction as a determinant of processing speed. Psychonomic Bulletin \& Review, 13, 619-625.

Mace, J. (2006). Episodic remembering creates access to involuntary conscious memory: Demonstrating involuntary recall on a voluntary recall task. Memory, 14, 917-924.

MacLeod, C. M. (1991). Half a century of research on the Stroop effect: An integrative review. Psychological Bulletin, 109, 163-203.

Madigan, S. (1983). Picture memory. In J. C. Yuille (Ed.), Imagery, memory, and cognition: Essays in honor of Allan Paivio (pp. 65-89). Hillsdale, NJ: Erlbaum.

Mandler, G. (1980). Recognizing: The judgment of previous occurrence. Psychological Review, 87, 252-271.

Marsh, R. L., Meeks, J. T., Cook, G. I., Clark-Foos, A., Hicks, J. L., \& Brewer, G. A. (2009). Retrieval constraints on the front end create differences in recollection on a subsequent test. Journal of Memory and Language, 61, 470-479.

Mayr, U., \& Kliegl, R. (2000). Task-set switching and long-term memory retrieval. Journal of Experimental Psychology. Learning, Memory, and Cognition, 26, 1124-1140.

Milham, M. P., Erickson, K. I., Banich, M. T., Kramer, A. F., Webb, A., Wszalek, T., et al. (2002). Attentional control in the aging brain: Insights from an fMRI study of the stroop task. Brain and Cognition, 49, 277-296.

Morcom, A. M., \& Rugg, M. D. (2004). Effects of age on retrieval cue processing as revealed by ERPs. Neuropsychologia, 42(11), $1525-1542$.

Moscovitch, M. (1994). Cognitive resources and dual-task interference effects at retrieval in normal people: The role of the frontal lobes and medial temporal cortex. Neuropsychology, 8, 524-534.

Moscovitch, M., \& Melo, B. (1997). Strategic retrieval and the frontal lobes: Evidence from confabulation and amnesia. Neuropsychologia, 35, 1017-1034.

Mutter, S. A., Naylor, J. C., \& Patterson, E. R. (2005). The effects of age and task context on Stroop task performance. Memory \& Cognition, 33, 514-530. 
Norman, D. A., \& Bobrow, D. G. (1979). Descriptions: An intermediate stage in memory retrieval. Cognitive Psychology, $11,107-123$.

Paivio, A. (1969). Mental imagery in associative learning and memory. Psychological Review, 76, 241-263.

Paxton, J. L., Barch, D. M., Racine, C. A., \& Braver, T. S. (2008). Cognitive control, goal maintenance, and prefrontal function in healthy aging. Cerebral Cortex, 18, 1010-1028.

Roediger, H. L., III. (1990). Implicit memory: Retention without remembering. The American Psychologist, 45, 1043-1056.

Rossion, B., \& Pourtois, G. (2004). Revisiting Snodgrass and Vanderwart's object pictorial set: The role of surface detail in basic-level object recognition. Perception, 33, 217-236.

Rowe, G., Valderrama, S., Hasher, L., \& Lenartowicz, A. (2006). Attentional disregulation: A benefit for implicit memory. Psychology and Aging, 21, 826-830.

Schacter, D. L., Israel, L., \& Racine, C. (1999). Suppressing false recognition in younger and older adults: The distinctiveness heuristic. Journal of Memory and Language, 40, 1-24.
Shipley, W. C. (1986). Shipley institute of living scale. Los Angeles: Western Psychological services.

Skinner, E., \& Fernandes, M. A. (2008). General and material-specific interference effects of divided attention at retrieval on remembering and knowing. Acta Psychologica, 127, 211-221.

Spieler, D. H., Balota, D. A., \& Faust, M. E. (1996). Stroop performance in younger adults, healthy older adults, and individuals with senile dementia of the Alzheimer's type. Journal of Experimental Psychology: Human Perception and Performance, 22, 461-479.

Ste-Marie, D. M., \& Jacoby, L. L. (1993). Spontaneous versus directed recognition: The relativity of automaticity. Journal of Experimental Psychology. Learning, Memory, and Cognition, 19, $777-788$.

Stroop, J. R. (1935). Studies of interference in serial verbal reactions. Journal of Experimental Psychology, 18, 643-662.

Yonelinas, A. P. (2002). The nature of recollection and familiarity: A review of 30 years of research. Journal of Memory and Language, 46, 441-517. 